\title{
Efficacy of thoracic paravertebral nerve block for patients who undergo video-assisted thoracoscopic surgery - randomised controlled trial-
}

\author{
Hironobu Ueshima ${ }^{1}$, Hiroshi Otake ${ }^{1}$, Mari Ichimura ${ }^{1}$, Akira Kitamura ${ }^{2}$ \\ 1 Department of Anesthesiology, Showa University Hospital, Tokyo, Japan. \\ 2 Department of Anesthesiology, Saitama international medical center, Saitama, Japan
}

\section{【Introduction】}

oThere were a few reports which investigated the analgesic efficacy and the safety for the thoracic paravertebral nerve block (TPVB) for the thoracic surgery.

oWe investigated the analgesic efficacy of the TPVB in videoassisted thorascoscopic surgery compared with the thoracic epidural analgesia.

\section{【Material and Method】}

Study type: A prospective study divided into $\mathrm{E}$ and $\mathrm{T}$ groups Condition: video-assisted thorascoscopic surgery

Study period: From July 2013 to July 2014

Excluded cases: cases having corrective secondary surgery, an allergic reaction to levobupivacaine, and cases having severe heart, renal or liver dysfunction

E group: general anesthesia and continuous epidural anesthesia block

T group: general anesthesia and continuous TPVB

\section{【Flow chart】}

TPVB or Epi

Each catheter was inserted into paravertebral or epidural space

between the $5^{\mathrm{th}}$ and $6^{\mathrm{th}} \mathrm{rib}$, or the $6^{\mathrm{th}}$ and $7^{\mathrm{th}}$ at the back

General Anesthesia

Anesthesia was maintained with total intravenous anesthesia (propofol and

remifentanil). Rocuronium was administered at the discretion of the anesthetists.

Additional $50-100 \mu \mathrm{g}$ fentanyl boluses were administered to maintain blood pressure or

heart rate value sings obtained when the patient entered the operation room

At the closed chest

$20 \mathrm{~mL}$ of $0.375 \%$ levobupivacaine was injected from the catheter inserted into the paravertebral or epidural space. Then the catheter was attached to a $\mathrm{CADD}^{\mathbb{R}}$-Solis PIBs (CADD, Smith Medical Japan Ltd., Tokyo, CADD), which are patient-controlled analgesia devices. The set flow rate of CADD was with a continuous infusion of $6 \mathrm{~mL}$ levobupivacaine $(0.125 \%)$ every hour.

At the end of the surgery, fentanyl $2 \mu \mathrm{g} \cdot \mathrm{kg}-1$ was infused intravenously. The CADD, in the Program Intermittent Bolus delivery mode was used to deliver $20 \mu \mathrm{g}$ of fentanyl intravenously outside of a 10 minutes interval for 2 days.

oThe primary outcome measured was the number of injected fentanyl boluses during the first 24 hours after surgery.

oThe secondary outcome measured was the number of required additional fentanyl doses. A numerical rating scale (NRS) was used to determine a pain score during the first 24 hours after surgery.
【Result】

\begin{tabular}{|c|c|c|}
\hline & $\begin{array}{c}\text { Egroup } \\
(\mathrm{n}=40)\end{array}$ & $\begin{array}{c}\text { Tgroup } \\
(\mathrm{n}=40)\end{array}$ \\
\hline $\begin{array}{c}\begin{array}{c}\mathrm{Age} \\
\text { (years) }\end{array} \\
\text { (a) }\end{array}$ & $\begin{array}{c}65 \\
(24-79)\end{array}$ & $\begin{array}{c}69 \\
(54-83)\end{array}$ \\
\hline$\underset{\left(\mathrm{kg} / \mathrm{m}^{2}\right)}{\mathrm{BMI}}$ & $\begin{array}{c}23.0 \\
(13.5-37.0)\end{array}$ & $\begin{array}{c}22.0 \\
(19.2-31.6)\end{array}$ \\
\hline $\begin{array}{c}\text { ASA classification } \\
(\mathbb{I} / \mathbf{I I})\end{array}$ & $5 / 35$ & $3 / 37$ \\
\hline $\begin{array}{c}\text { Anesthesia time } \\
(\text { (min) }\end{array}$ & $\begin{array}{l}257.5 \\
(185-365)\end{array}$ & $\begin{array}{c}202.5 \\
(125-305)\end{array}$ \\
\hline$\underset{(\min )}{\text { Operation time }}$ & $\begin{array}{l}2007 \\
(150-340)\end{array}$ & $\begin{array}{l}150 \\
(105-255)\end{array}$ \\
\hline $\begin{array}{l}\text { An amount of fentanyl } \\
\text { in perioperartite period } \\
(\mu \mathrm{gg})\end{array}$ & $\begin{array}{l}400 \\
(100-900)\end{array}$ & $\begin{array}{c}400 \\
(100-800)\end{array}$ \\
\hline $\begin{array}{l}\text { An amount of remifentanil } \\
\text { in perioperatitive period } \\
\text { (mg) }\end{array}$ & $\begin{array}{c}1.91 \\
(0.2-4.27)\end{array}$ & $\begin{array}{l}1.68 \\
(0.1-5.46)\end{array}$ \\
\hline
\end{tabular}

$\langle$ Number of fentany boluses〉

〈Pain Scores〉

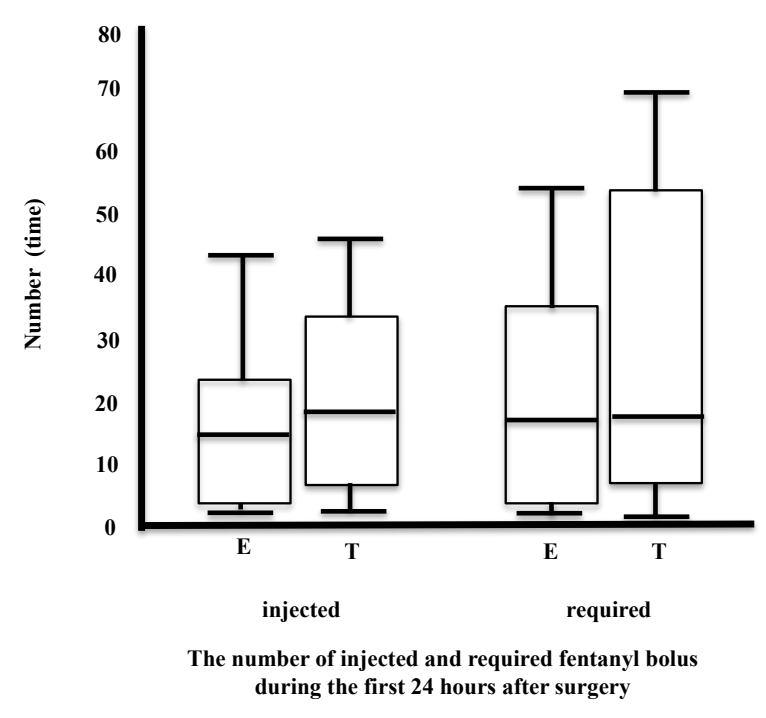

\begin{tabular}{|c|c|c|c|c|c|c|c|}
\hline rest & $\mathrm{E}$ & $\mathrm{T}$ & P-value & move & $\mathrm{E}$ & $\mathrm{T}$ & P-value \\
\hline 1 & $\begin{array}{c}0 \\
(0-4)\end{array}$ & $\begin{array}{c}2 \\
(0-3.25)\end{array}$ & 0.68 & 1 & $\begin{array}{c}0 \\
(0-4)\end{array}$ & $\begin{array}{c}3 \\
(0-3)\end{array}$ & 0.13 \\
\hline 2 & $\begin{array}{c}0 \\
(0-4)\end{array}$ & $\begin{array}{c}3 \\
(0-4)\end{array}$ & $<0.05$ & 2 & $\begin{array}{c}0 \\
(0-4)\end{array}$ & $\begin{array}{c}3 \\
(0-5)\end{array}$ & $<0.05$ \\
\hline 4 & $\begin{array}{c}0 \\
(0-1)\end{array}$ & $\begin{array}{c}3 \\
(0-4)\end{array}$ & $<0.05$ & 4 & $\begin{array}{c}0 \\
(0-4)\end{array}$ & $\begin{array}{c}3 \\
(0-3.25)\end{array}$ & $<0.05$ \\
\hline 6 & $\begin{array}{c}0 \\
(0-2.25)\end{array}$ & $\begin{array}{c}3 \\
(0-3)\end{array}$ & $<0.05$ & 6 & $\begin{array}{c}3 \\
(0-3)\end{array}$ & $\begin{array}{c}3 \\
(0-3.25)\end{array}$ & 0.35 \\
\hline 12 & $\begin{array}{c}1 \\
(1-3)\end{array}$ & $\begin{array}{c}3 \\
(0-3)\end{array}$ & $<0.05$ & 12 & $\begin{array}{c}3 \\
(0-5)\end{array}$ & $\begin{array}{c}3 \\
(0-4)\end{array}$ & 0.68 \\
\hline 18 & $\begin{array}{c}1 \\
(1-3)\end{array}$ & $\begin{array}{c}3 \\
(0-4)\end{array}$ & $<0.05$ & 18 & $\begin{array}{c}3 \\
(0-5)\end{array}$ & $\begin{array}{c}3 \\
(0-5)\end{array}$ & 0.27 \\
\hline 24 & $\begin{array}{c}1 \\
(1-2)\end{array}$ & $\begin{array}{c}3 \\
(0-3)\end{array}$ & $<0.05$ & 24 & $\begin{array}{c}4 \\
(0-5)\end{array}$ & $\begin{array}{c}4 \\
(0-5)\end{array}$ & 0.37 \\
\hline
\end{tabular}

\section{【Discussion】}

The TPVB is as effective as the epidural analgesia in videoassisted thoracoscopic surgery.

The spread of local anesthetic for TPVB is almost the same as epidural anesthesia. Considering that epidural anesthesia is a landmark technique, ultrasound guided-TPVB may be safer than the epidural analgesia in video-assisted thoracoscopic surgery.

\section{【Conclusion】}

The number of injected fentanyl bolus to the T group was equal to the E group.

The TPVB is as effective as the epidural analgesia in videoassisted thoracoscopic surgery.

Acknowledgements relating to this article

Assistance with the letter: none.

Financial support and sponsorship: none.

Conflict of interest: none. 